\title{
INENIGMÁTICA: O DESLOCAMENTO DO LEITOR NO CORPO DA POESIA BRASILEIRA CONTEMPORÂNEA
}

\author{
INENIGMÁTICA: THE DISPLACEMENT OF THE READER \\ IN THE CONTEMPORARY BRAZILIAN POETRY
}

\author{
Jacimara Vieira dos Santos
}

\begin{abstract}
Resumo: A literatura brasileira contemporânea, em seus diversos gêneros, opera deslocamento de termos, lugares e teorias com as quais estamos familiarizados, mobilizando, inclusive, outras formas de comunicação com o público leitor. Em Inenigmática (2014), Dilson Solidade Lima, por meio da constituição dos sujeitos poéticos, acena para o lugar do leitor na instância criativa da poesia. Este estudo analisa a potência comunicativa da obra, observando a composição de sutis jogos de leitura que conduzem ao deslocamento do leitor, de seu suposto lugar de passividade contemplativa. Concomitantemente, propõe o debate sobre os campos teóricos tradicionais acerca dos lugares consagrados a cada um.
\end{abstract}

Palavras-chave: poesia brasileira contemporânea, leitor, Inenigmática, Dilson Solidade Lima

Abstract: The contemporary Brazilian literature, in its various forms, moves the terms, expressions and theories that we are familiar with, mobilizing even other forms of communication with the readers. In Inenigmática (2014), Dilson Solidade Lima, through the poetic persona, shows the importance of the reader to the literary creation process. This study analyzes the communicative force way of the literary work, more specifically, to the act of poetical creation, in the interesting play with readers and their presumed passive or contemplative position. Concomitantly, proposes a discussion about traditional theoretical areas and the places consecrated to each one.

Keywords: contemporary brazilian poetry, reader, Inenigmática, Dilson Solidade Lima

\footnotetext{
* Mestre em Literatura e Diversidade Cultural pela Universidade Estadual de Feira de Santana (UEFS) e doutora em Letras pela Universidade Federal da Bahia (UFBa).
} 
entre os gêneros literários, há muito hibridizados, mas dos quais ainda se pode buscar especificidade, a poesia se destaca enquanto problematizadora de seu tempo, pois que se reconhece preterida no sentido mercadológico. Ao passo que se multiplica em livros materiais e em meios virtuais, gráficos e visuais; também amplifica sua capacidade comunicacional, atravessa fronteiras, chega a muitos e, contraditoriamente, algumas vezes parece ser para poucos.

Com relação a aspectos mais gerais que cercam questões da escrita nos tempos atuais, Beatriz Resende (2008, p.12), ao examinar o conjunto de aspectos e evidências relativas à literatura brasileira contemporânea, afirma:

A primeira evidência que salta aos olhos diante do objeto escolhido, e que gostaria de apontar para começar, é a fertilidade dessa forma de expressão entre nós, hoje. Apesar das queixas repetidas de que há poucos leitores, de que o livro vende pouco, etc., é fácil constatar que se publica muito, que novos escritores e editoras surgem todos os dias, e que comenta-se e consome-se literatura. Nas grandes cidades, novas livrarias partilham o mesmo espaço com outras formas de lazer, tornando o convívio com o livro mais sedutor.

A literatura circula enquanto objeto de consumo, sem se deixar vencer necessariamente apenas por uma lógica capitalista, fazendo-se visível e presente em vários espaços da sociedade, sob os domínios do lazer, da cultura, do entretenimento, do universo acadêmico e em múltiplos espaços. Nesta multiplicidade de lugares, presume-se a existência dos leitores, igualmente pluralizados em seus perfis configurativos, marcados por sua época e pelos elementos particulares de que é contemporâneo.

Sob tais constatações, a ideia de que "novos escritores e editoras surgem todos os dias e que comenta-se e consome-se literatura" faz entrever certa dinâmica no circuito da criação literária e no panorama que se mostra em evidente desafio ao cânone, menos por confronto deliberado que por força de sobrevivência paralela. Os leitores contemporâneos, portanto, têm à sua disposição opções incontáveis de obras e acesso diversificado a elas, em razão da multiplicidade de meios - especialmente os digitais.

Neste contexto, Inenigmática (2014), do escritor baiano Dilson Solidade Lima, por meio de uma contundente potência comunicativa, mobiliza a composição de sutis jogos de leitura, de forma a forçar o deslocamento do leitor, retirando-o de 
seu suposto lugar de passividade contemplativa e, ao mesmo tempo, perfaz as ramificações dos campos teóricos tradicionais acerca dos lugares consagrados a cada um (autor, leitor). Sob tal direcionamento, articula-se com a proposição de Iser (1996, p. 15), ao reforçar a importância qualitativa do leitor, segundo a qual o texto se constitui como "um potencial de efeitos que se atualiza no processo de leitura."

Conforme se pode inferir a partir da obra, há um convívio profícuo entre experimentação e tradição; articulação sintática e pluralidades referenciais; e (im) posturas da persona poética que, cinicamente, ficcionaliza o leitor, sem a menor preocupação em evitar a colisão frontal com o universo extraliterário.

Sabe-se que prevalecem sintagmas (recorrentes e complexos) na discussão ora proposta, em especial no que tange a o que é um leitor e à morte do autor, de que não se pode descurar, mas que julgamos já ser de domínio geral e, deste modo, não será alvo de discussão direta neste estudo.

Torna-se necessário advertir que essas coincidências conceituais nem sempre vão se operar na obra em lide. Consequentemente, o que se pode asseverar do sujeito poético que se pronuncia em Inenigmática é sua atenção e clareza acerca da existência do leitor frívolo, casual e desatento ao qual se oporia o leitor ideal ou preparado (postos, ambos em seus limites). Tais constatações muito se aproximam do que propõe Ricardo Piglia (2006, p. 21), em $O$ último leitor:

O leitor viciado, aquele que não consegue deixar de ler, e o leitor insone, o que está sempre desperto, são representações extremas do que significa ler um texto, personificações narrativas da complexa presença do leitor na literatura. Eu os chamaria de leitores puros; para eles, a leitura não é apenas uma prática, mas uma forma de vida.

Conforme as assertivas de Piglia, a existência plena da literatura só se consubstancia mediante a ação do leitor, ao tomar-lhe as páginas, vivificando as palavras e os sentidos que, em contrapartida, inserem também o leitor no universo ficcional.

Inenigmática compõe-se por 97 criações poéticas, cada qual com exigências peculiares de leitura. Deste universo foram escolhidos seis poemas, nem todos tomados na íntegra, julgados mais representativos para a discussão proposta, 
em que pesem inegáveis questões subjetivas de que não está imune o trato acadêmico-científico (bem como suas leituras).

O poema de abertura do livro oscila entre deambulações internas do sujeito poético e as externalidades da paisagem urbana, à qual este se rende. No engarrafamento (p. 17), desvenda-se a cidade:

Entre traços

de amor na noite

esta tarde

que não dorme

e ternamente

horizontes

mapeia

esculpe

ausculta

em meio

a apneias

lusco-fuscos

sexos estômagos

repartido olor

de rodas-tráfego

essa essência verde

pela pele

branca da parede

(o musgo)

em síncopes de parto

à limos que se the

viscosamente

vestem

abre-se entre outros

microlaivos

que da penumbra

mil vírgulas avistam

com suas lupas

milimétricas 
enquanto sacamos

a vida num banco.

Há uma multiplicidade de imagens-símbolos a confundir o primeiro verso, pretensamente temático do amor, às asperezas e abjeções do cenário urbano. As cores do cenário fazem com que se destaque a parede branca repleta do limo que lhe (re)veste; o lusco-fusco parece desencantador, opondo-se à imagem comum do espetáculo crepuscular e a penumbra que obscurece a cidade e seus signos: quase que se pode prenunciar verdadeira poluição. Na confluência da mensagem poética, as imagens que sobrevém fazem entrever que respirar a cidade é sufocar o amor, que suscita uma parada momentânea (apneia) - tempo do leitor respirar ou se permitir sufocar pela profusão de imagens superpostas.

$\mathrm{Na}$ ambiguidade de sentidos proposta nos últimos versos, talvez uma pequena chave do enigma poético que se anuncia ao leitor: "enquanto sacamos/a vida num banco" (ibid.,p.17). Sob este ponto, podemos nos apegar ao imediato, de uma sociedade capitalista, em que tudo é mercadoria e a vida custa muito e, ao mesmo tempo, não vale nada em certas circunstâncias do cotidiano urbano. Entretanto, o jogo com o termo sacar, por sua conotação em gíria que significa 'retirar um sentido', 'entender', revela-se como complementar à ideia de banco - que pode ser não somente a entidade financeira, mas o banco onde se senta para contemplar, abstrair, devanear e pensar. No clichê urbano e cotidiano de que tempo é dinheiro, quem poderia dispor do tempo para sacar a vida impunemente? Jogo reiterado na construção de sentidos que esbarram no leitor.

Convém frisar a confiabilidade presumida pelo sujeito poético frente à recepção de sua leitura da cidade, por parte do leitor propriamente dito. Assinala-se um intercâmbio de lugares, com efeito metacrítico, pois que o poeta se mostra leitor e, ao assumir a leitura que faz dos signos da cidade, está, também, exposto à vulnerabilidade de fazer uma leitura (im)pertinente. Entretanto, toda leitura opera-se por um prisma, um dado recorte, um modo de apreender símbolos, signos e acrescentar-lhes, portanto, significados. A leitura apresentada pelo sujeito poético é ácida e materializada na massa comum e conhecida dos signos e da vida da cidade. Por outro lado, a cidade imputa o convívio com a palavra impressa, vulgarizada e mercantilizada em panfletos e propagandas que chegam à mão do leitor, em meio ao tumulto da cidade - mensagens, muros, placas, outdoors, na infinidade de papéis destinados a si. Poderíamos, ainda, pressupor 
que, ciente de todos esses fatores, o poeta anseia por um leitor idealizado e dialoga silenciosa e imaginariamente com ele. Defende-se, contudo, que essa figura do leitor tem uma representação presumível, a partir do vínculo inegável que se estabelece entre obra e público leitor.

A transubstanciação da palavra cotidiana mais simples em substrato poético reaparece no poema seguinte, Um punhado de nada ( p. 18), a adentrar o universo metafísico com a percepção das tonalidade afetivas que opõem Ser e Nada:

Cantante pedra à beira do caminho,

o rio que amanhece no horizonte, a fonte de eterna luz, a ponte/ as palavras de amor em burburinho.

o cálice sagrado, o doce vinho, as pérolas do mar, o sol dos montes, a pétala estelar - Belerofonteos cânticos de paz, os passarinhos

e as instabilidades, os nervos fortes, o vômito e a vingança violentos à cólera escumar: íris da morte

que na noite faísca envolto e pênsil...

E a calma revolvente, a santa sorte:

bálsamo sonante à alma de silêncios.

Encontra-se, aqui, o nada enquanto evocação dos limites do que pode ser nomeável no subsolo das palavras. A expressividade lírica estabelece um ritmo de paz e calma, elegendo imagens de natureza harmônica (rio, luz, palavras de amor, pérolas, paz, passarinhos...), convidando o leitor à tranquilidade.

O conteúdo poético de Um punhado de nada, entretanto, oscila da doçura singela do primeiro quarteto - "Cantante pedra à beira do caminho,/o rio que amanhece no horizonte,/a fonte de eterna luz, a ponte/as palavras de amor em burburinho..." (ibid., p.18) - para a violenta e grotesca expressividade de seu últi- 
mo terceto: "e a instabilidade, os nervos fortes/o vômito e a vingança violentos/à cólera escumar: íris da morte".

Contrariando o título do livro, o nada continuará a ser enigmático, reportando ao vazio, à ausência, à falta e à inexistência e, também, apontando à direção final da existência, do não-ser. Assim, movimentam-se na poesia o ser, o nada, a morte, as doçuras e o amargor.

O sujeito poético também atua de maneira provocativa, pois que, em parte substancial de seus poemas, ao dispor de referências de domínios teóricos majoritariamente pertencentes ao campo da filosofia, da arte e da mitologia, estimula a busca, por parte do leitor, dos significados e explicações concernentes a cada um; também invoca a mais tenra simplicidade de leitura, que pode priorizar somente os sons, os ritmos, as imagens, de forma a ultrapassar a significação vocabular e servir universalmente para decodificar as interseç̧ões das dores, dúvidas, gozos e fruições comuns ao ser vivente. Portanto, neste último caso, o poema pode ser lido a partir de sua sonoridade, dos efeitos imagéticos, do despertar de sentidos particulares e de apropriações ou empatias mediadas por certa identificação.

Ciente das relações seculares entre a poesia e a cidade, o leitor especializado, mas não somente ele, depara-se com requintada sintaxe para tratar de uma experiência conhecida e, paradoxalmente, sempre nova. A pluralidade de sentidos e a liberdade interpretativa de que dispõe permitem sustentar a suposição de que o poeta se valeu da expressividade regional (aqui é firmada a novidade da experiência conhecida pois que a cidade já não é a metrópole europeia da imagem clássica, mas a interiorana, subalternizada e pequeno-metropolitana do interior da Bahia) para erigir seu título, pois que dentre a variação regional nordestina consta a expressão 'de nada', a fim de mostrar o quão ínfimo é aquilo a que se está por referir, de maneira que encontramos sentenças como "um tantinho de nada"; "um pedacinho de nada"; "um bocado de nada", em que quase sempre a primeira expressão tem teor hipocorístico, a fim de reforçar a elocução.

Caberia, ainda, tomarmos esse processo como uma maneira irônica de pensar a postura da crítica literária, interessada em encaixar em quadros classificatórios, a literatura. A forma clássica do soneto Um punhado de nada enceta novo jogo de percepção com o leitor, alinhando as polêmicas subjacentes à defesa de que há sectarismos na literatura que, por sua vez, engendram as taxionomias utilizadas pelo cânone literário que afirmam haver literatura regional, na- 
cional, universal (aqui excluídas as classificações por gêneros, estilos e épocas, por exemplo). Nessa perspectiva, a voz poética parece questionar indiretamente o lugar da poesia - tanto aquele de onde ela provém, quanto aquele que the é atribuído pelo cânone, assim como o seu não-lugar, pois que a classificação de regional, por princípio, cai em aporia pois que toda região é um lugar e todo lugar é uma região, variando apenas a depreciação ou a valorização advindas de atributos simbólicos e mesmo geopolíticos. Deste modo, qualquer lugar é um lugar no mundo e a regionalização cairia no abismo de assim se chamar por tomar caracteres culturais de específicos locais.

Completando o ciclo inicial de poesias, Confissões a Politano (p. 19) sustenta, ainda, o mesmo tom inquiridor existencial contido nas criações anteriormente citadas:

Não tive sorte

no amor,

não tive sorte

nas cartas/

não tive sorte

e a morte

sempre

me acompanhou

desde muito cedo

com seu medo

- estilete

esterilizante-

que a hora certa

aguarda

de nos pular

à garganta.

Ao leitor apressado, talvez Politano pareça/apareça como um interlocutor, um nome próprio masculino, como seria concebível, talvez numa acepção biográfi- 
ca. Ao mais atento, remeterá a um provável morador da Pólis, um habitante da cidade, com seus dramas e dores banais ou banalizados pela recorrência.

No corpo do poema, entretanto, não se mostra o óbvio, mas se revaloriza o princípio de uma comum identificação, mesmo que seja somente a consciência de finitude que o sujeito poético joga na cara do leitor, sem esboçar polidez (nem urbanidade). Estabelece-se novo jogo poesia/percepção: o poema vem sustentado todo em primeira pessoa do singular (um eu oculto), para se pluralizar numa referência a nós (vide verso: "de nos pular/à garganta"), numa terceira pessoa - extrapolando o jogo retórico nos/nós pronominal até se substantivar em provável 'nós' de sufoco, em termos de amarras, imagens de enforcamento ou metáfora psíquico-afetiva de nós na garganta, no peito, pois que a morte também aguarda a hora de atingir todos (nós).

Em Regressão futura, a tônica do existir desenha-se na suavidade do verso "e a leve sensação de não se ser" (p. 20).

Como ponto de partida para qualquer leitor, toma-se o título e detecta-se o antagonismo nele expresso, que aduz a um regresso ao porvir (improvável, mas possível no universo poético - nos desdobramentos de um trato nonsense, sob tom de entropia) e traça uma desconstrução temporal que quebra a expectativa de linearidade, confundindo o antes e o depois, o que foi e o que será.

Pode-se considerar um recurso entrópico essa forma de quebra temporal, pois, segundo Sproviero,

A entropia é a inversão do tempo, ou seja, esse aspecto pelo qual quanto mais se regride no tempo, mais "intenso" é o tempo. E quanto mais se progride, mais "diluído" é o tempo. É o tempo em seu aspecto negativo: nós estamos acostumado a pensar no devir do cosmos como um vir-a-ser, mas, na verdade, trata-se de um regressivo deixar-de-ser sem aniquilar-se: "acumula-se um entulho de ser". Como mostram bem os físicos Bernhard e Karl Philbert, não só o espaço é a função do tempo, mas o próprio tempo é função do tempo. Não podemos pensar num tempo uniforme e linear e separado das coisas, mas num tempo entrópico, que se degrada com o tempo. (SPROVIERO, 2007, p. 05)

A calcificação dos argumentos propostos sugere a entropia orgânica, que marca a vida humana a nascer, crescer e se desenvolver, quando cada um desses passos representa um passo na direção do desgaste, da morte - ponto da encru- 
zilhada existencial aludida pelo poeta, reiterado nas imagens de saudade, num fluxo de indecibilidade de passado e presente.

Os opostos que são estabelecidos entropicamente, esboçados numa volta ao futuro, num regresso ao porvir, comunicam os abalos da lógica imediata, contidos no poema. Longe de constituir uma segurança para a própria voz poética que anuncia contrassensos no tempo, também o eco da palavra poética produzirá abalos sísmicos sob o chão do autor, que corre o risco constante da incompreensão, da interpretação insuficiente, da autonomia das leituras que, naturalmente, não se submetem às suas intenções e, mesmo, podem ir em sentidos imprevisíveis, contrariar as expectativas do autor e trair as projeções de recepção que ele venha a ter.

$\mathrm{Na}$ tessitura das imagens e nas escolhas da matéria verbal feitas para compor o texto poético o risco das provocações (aqui entendidas não somente no que toca a certo tom de insulto deliberado ao leitor e ao poder de compreensão que Ihe compete, mas nos termos de incentivo e estímulo) mostra-se recurso especulativo, como se no jogo da leitura, o sujeito poético (assim como o próprio autor), procurasse antever ou prever o passo do leitor. Todavia, não há garantias. Ciente disso, o sujeito poético faz lances arriscados, revertendo sentidos, quebrando a lógica, nivelando opostos, traçando similitudes inconciliáveis, assumindo, muitas vezes, enlaces com as contradições, indo ao encontro da seguinte proposição de Octavio Paz:

Certo, nem em todas as imagens os opostos se reconciliam sem se destruir. Algumas descobrem semelhanças entre os termos ou elementos de que se compõe a realidade: são as comparações, segundo Aristóteles as definiu. Outras aproximam "realidades contrárias" e produzem assim uma "nova realidade", como diz Reverdy. Outras provocam uma contradição insuperável ou um sem-sentido absoluto, que denuncia o caráter irrisório do mundo, da linguagem ou do homem (a essa classe pertencem os disparos do humor e, já fora do âmbito da poesia, as piadas). (PAZ, 1982, p. 136)

O sem-sentido absoluto (nonsense) de que nos fala Paz aponta para a liberdade criativa do escritor na edificação do poema, atuando como modo de expor a própria ausência de lógica no mundo, em muitos eventos que aliam e desaliam as bases da causalidade e da casualidade - nem tudo é explicável, nem tudo é 
compreensível. Desta forma, ao longo de Inenigmática, extraordinárias amplificações de imagens temporais vão marcar os poemas, de modo a subverter a própria concepção comum ou familiar de tempo cronológico.

Outro poema, intitulado Missiva aos meus (p. 21), assinala certa condensação espaço-afetivo do poeta com a cidade, metaforizada em ícones particulares, como nos versos: "A cidade sou eu em suas casas, /praças, currais, becos, avenidas, /bostas de bois, aboios e boiadas...". O sujeito poético declara identificação e fusão com a cidade antagonicamente travestida da metrópole em que se tornou.

A aliteração em /b/ passa a funcionar como indicador de balbucio e remete à sonoridade própria a buzinas, onde o valor expressivo do som depende, mais uma vez, da percepção do leitor e da sua predisposição a captar o poema a partir de uma leitura múltipla, que ultrapasse palavras e versos e possa repousar também na trama sonora que, neste caso, acentua os sentidos do eco da cidade em trânsito.

A cidade bifronte oscila entre o desenvolvimento urbano e os traços rurais, na visão oferecida pelo poeta: "Sua insistente carroça no trânsito devorador!" verso que faz subentender os descompassos da urbe, o convívio pouco pacífico entre os seus elementos constitutivos e a possibilidade de que o avanço urbano atropele os cidadãos e viva a colidir com os anacronismos também inconciliáveis.

Os medos e problemas de cidade grande parecem fomentar as inseguranças e dores do crescimento: "A cidade com seus muros/mitos lendas se fecha em/ chaves grades cadeados cães/de guarda cerca elétrica/vigilância satelítico/ monitoramento 25 h...". Desencantam-se os mitos e as lendas da cidade: parte simbólica da composição identitária do lugar, cede espaço para a realidade (cidade que se cerca e se fecha).

Torna-se emblemática a questão do olhar e da vigilância: preventivamente, é necessário estar atento para estar seguro. Convergindo para esse estado de tensão, todo aparato possível para se cercar de segurança não cabe sequer num dia: são necessárias vinte e cinco horas de monitoramento. Parece, contudo, que a segurança se resume a uma sensação, não a uma realidade concreta.

Dispersos na obra, os símbolos da cidade - que é toda, qualquer uma e uma em específico (Feira de Santana) - propõem a observância e a cautela ao valor dos lugares e à tipificação que Ihe dá corpo. $O$ poeta das metrópoles deambu- 
la em viagens interiores e viagens pelos interiores (a cidade do interior baiano revelada no interior da imagem-poesia), manobrando e guiando os passos do leitor que, quanto mais desavisado, mais propenso estará a cair nos abismos semântico-simbólicos e, mesmo, a reduzir suas constatações a quesitos fixos que tangem ao regionalismo ou ao localismo, por ignorar o que personifica a paisagem urbana e o que se universaliza a partir da linguagem poética.

A ideia epistolar implícita na 'missiva' é traída por ser, na verdade, uma carta aberta, pretensamente destinada aos íntimos ('aos meus'), mas que se sabe devassada pelos leitores.

Ainda no que toca à tensão entre leitura da cidade e experiência imaginativa, observe-se que em Olhos d'água (p. 91), título que, por si só, carrega a poeticidade - das águas às lágrimas -, a cidade é lida pelos olhos do poeta.

Textualizada e descortinada nas referências sobre sua historicidade, imersa na liquidez mansa que envolve o viver contemporâneo, Feira de Santana, surge tematizada na obra, amparada na história oficial, como a sancionar pacto com a verdade instituída: cidade nascida a partir da fazenda em que havia uma capela à Santa Ana dos Olhos D’Água, à medida que cresce, amparada pela vocação comercial, vai sendo profanada pela expansão da economia: "Rainha, Cortesã.../ Comercialíssima manhã!/Província...Princesa!/Quem lhe porá o anel na mão esquerda?"

A cidade é santa e comercial, pura e cortesã, tendo recebido epíteto de "Princesa do Sertão", vivencia as ambiguidades de ser plebeia e majestosa, ser grande e provinciana, disposta aos muitos que lhe façam a corte, pois que, entrecruzada por rodovias, recebe muitos visitantes. A partir das topografias, das referências à disposição espacial, o poeta propõe conexões, oferecendo sua leitura particular e abrindo a possibilidade de recomposição de sentidos por parte do leitor.

Ao colocar-se como menestrel, o poeta espreita a cidade (personificada) e capta os seus códigos permutados em significantes, em minucioso trabalho de composição criativa, confundindo-se, por vezes, com ela. É mítico e místico andarilho que sabe conjurar os poderes da escrita, que nesse processo revela a verdade mascarada: há um autor transfigurado na voz poética, que está a lidar com um universo plural e (im)previsível de leitores. Neste sentido, podemos asseverar, conforme indica Michel Foucault, que: 
Seria absurdo negar, é claro, a existência do indivíduo que escreve e inventa. Mas penso que - ao menos desde uma certa época - o indivíduo que se põe a escrever um texto no horizonte do qual paira uma obra possível retoma por sua conta a função do autor: aquilo que ele escreve e o que não escreve, aquilo que desenha, mesmo a título de rascunho provisório, como esboço da obra, e o que deixa, vai cair como conversas cotidianas. Todo este jogo de diferenças é prescrito pela função do autor, tal como ele a recebe de sua época ou tal como ele, por sua vez, a modifica. Pois embora possa modificar a imagem tradicional que se faz de um autor, será a partir de uma nova posição do autor que recortará, em tudo que poderia ser dito, em tudo o que diz todos os dias, o perfil ainda trêmulo de sua obra. (FOUCAULT, 2008, p. 28-29)

Deste modo, o leitor completa a obra que jamais será completa, ainda que esteja finda. O jogo, então, é reconduzido, ultrapassando os limites da decifração textual, em si, mas vindo a atingir o status do autor - que, sob nova posição, precisa difundir sua obra, ser conhecido, ser reconhecido, dispor de fortuna crítica, transitar nos meandros hostis do cânone e ter traquejo no mercado editorial e nas redes de difusão.

Foucault afirma que "na ordem do discurso literário" a função do autor, ao contrário do que ocorreu em outros campos, veio a se reforçar a partir da Idade Média. Assim sendo, de seus escritos

[...] pede-se-lhe que revele, ou ao menos sustente, o sentido oculto que os atravessa; pede-se-Ihe que os articule com sua vida pessoal e suas experiências vividas, com a história real que os viu nascer. $\mathrm{O}$ autor é aquele que dá à inquietante linguagem da ficção suas unidades, seus nós de coerência, sua inserção no real. (ibid., p. 27-28)

O leitor tem a expectativa de que o autor possa dar conta de todas as respostas possíveis quando, por outro lado, é ele quem redireciona os sentidos e ao se apropriar da obra propõe focos, acepções, concepções, preenche lacunas e dá sustentação a outra camada da criação, assentada na crítica que faz.

Conforme podemos acompanhar, se o autor busca um leitor ideal ou, mais precisamente idealizado, ele ficcionaliza esse público. Pode, ainda, mostrar-se voltado deliberadamente a determinado segmento de público leitor, tanto em 
nível mercadológico (ao qual cabem adjetivações cuja coerência é antes comercial que literária, num universo extenso, do tipo: Literatura infanto-juvenil; ficção, romance; etc., e cujo enquadramento, frisamos, atende a classificações do mercado), quanto em nível ideológico, colocando-se como artefato para determinados setores socioculturais e a tipos determinados de perfis.

Não esqueçamos, ainda, que no tocante ao poema, não obstante sua origem (lírica), é possível declamar. Esse processo de oralidade perpassa a fixação escrita, acrescenta-Ihe tom e som, dramaticidade e interpretação, ofertando, assim, uma leitura (particularizada).

No cerne de Inenigmática, encontram-se poemas densos em sentido, com orientações plurais. Naturalmente, a forma para a eleição dos poemas em estudo perpassa, conforme anteriormente afirmado, critérios subjetivos por parte de quem, no caso, se pronuncia como leitor cuja acepção e abordagem literárias primam pelo teor científico. Decorre de tais fatores a implícita inquirição a respeito das escolhas que compõem o corpus do trabalho - por que este autor? Por que esta obra? Como ocorreu o acesso a ambos ? $^{1}$ - dentre outras questões plausíveis que, a seu tempo, vão aparecer sob a forma metodológica especificamente delineada em objetivos e justificativas, conforme exigências científicas já citadas.

Como último poema escolhido para ilustrar este estudo, passemos a Pela crúcis (p. 22), observando que o sujeito poético distorce e trai a expectativa contida na previsibilidade do ditado popular ("Cada um com sua cruz"), mas não se põe acima das vicissitudes que cercam o ser humano em geral (cristão, filho de Deus). A leitura do evento bíblico guarda teor apócrifo, em processo de dessacralização que indica muito mais a situação de erraticidade do sujeito poético do que se presta a mero devaneio herético:

Cada qual com sua luz.

Quem não a leva

carrega

o fardo

\footnotetext{
${ }^{1}$ Há que se esclarecer que também neste ínterim há certa ficcionalização sobre quem escreve e um modo comum de destacar a aresta extraliterária é perscrutar os lugares de verdade e realidade em que se deram o contato com o autor e com a obra.
} 


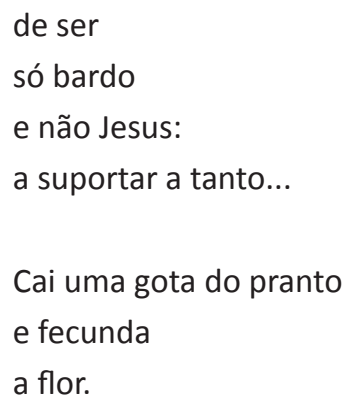

Os desvios do caminho da previsibilidade anteriormente reportados instauram outra experiência de leitura e de deleite, enquanto estimulam um tráfico paralelo de interpretação e cooptação de sentidos e imagens.

Ser só bardo não atenuará o peso da luz/cruz, com as ambíguas consequências que faz suportar e, "De ira em ira, de amor em amor", o humano se mostra sem mistério, sem efeitos especiais na existência de cada ser: longa é a estrada pela qual se tem que caminhar. As cenas traçadas do calvário particular apenas nos distinguem pela consciência da finitude, das dores, das angústias e da efemeridade dos eventos felizes. 
Pode-se inferir que, no cerne deste feito, nada há de extraordinário: apenas mais um escritor/autor, com usufruto pleno de palavras cotidianas, cenas comuns, escrita inserida num universo de pares similares, inscrito no circuito cultural e mercadológico que contorna a época atual. O extraordinário, porém, está na apropriação do comum de um modo particular e na assunção/inserção deste e neste lugar, sem que isto seja concebido como vetor de inferiorização ou de desqualificação do trabalho de criação poética. O poeta é mais um cristão, comum, carente de luz de projeção, sem um altar no cânone. Maldito, aponta o caminho da perdição na leitura que ora ilude por tomar o simples por referência e dar pistas de que não há enigma, mistério, segredos ou sentidos ocultos, mas há, antes, a indicação de que o óbvio sempre pode surpreender - o que alimenta a vontade de decifrar.

Ao deixar o leitor vulnerável aos signos, consegue retirá-lo da suposta passividade de quem apenas contempla. Do passeio pelas páginas da obra pode surgir um leitor inseguro ou inconformado com o óbvio, que se sente desafiado a extrair sentidos e tornar inesgotável o escrutínio em relação à obra. Na interdependência das partes, quem cria e escreve está suscetível a quem lê.

Costuma-se dividir as partes da recepção das obras em crítica e público - apesar de ambos serem leitores substanciais, ocupados no deciframento e na reconstrução de sentidos. Ricardo Piglia aduz a dois tipos principais de leitores em confronto: o criminoso e o detetive. Com o primeiro identifica a leitura da crítica:

O leitor como criminoso, que utiliza os textos em benefício próprio e faz deles um uso indevido, funciona como um hermeneuta selvagem. Lê mal, mas apenas no sentido moral; faz uma leitura rancorosa, faz um uso pérfido da letra. Poderíamos pensar na crítica literária como um exercício desse tipo de leitura criminosa. Lê-se um livro contra um autor. Lê-se a leitura inimiga. O livro é um objeto transacional, uma superfície sobre a qual se deslocam as interpretações. (PIGLIA, 2006, p. 34)

Piglia está tratando sobre a figura oposta ao leitor inocente, mas destacando, com alguma dose de meta-referencialidade, o quanto a leitura operada pela crítica formal tende a ser excludente e suspeita. A crítica fundamenta uma visão particular da obra, cristaliza o tom da recepção - razão pela qual, exerce poder e desperta temor por parte dos que escrevem. 
Disso não se conclua, porém, a inexistência de fortuna crítica consolidada e premiações conquistadas por Dilson Solidade Lima, no transcurso de sua vida de escritor. A busca por correlação entre o escrito e o vivido, busca pelo lugar onde a realidade foi e está depositada, as inversões e alterações de nexo se conciliam com a constatação, nada incomum, do que o autor é como leitor - papel que ele desempenha e conhece.

Michel de Certeau afirma que uma obra de valor é aquela que tem o reconhecimento de seus pares. Certamente, o conceito de valor é algo mutável, relativo e múltiplo - e sabemos que o autor se refere à escrita formal, tanto da história quanto da literatura. Ao apontar sentidos amplos sob a organização de significantes no plano da representação, defende a articulação da prática com a escrita - cuja discussão, por sua vez, encadeia análises paritárias com o tema ora trazido, particularmente no que tange à vivificação e mobilização do leitor:

Na verdade, a função específica da escrita não é contrária, mas diferente e complementar com relação à função da prática. Ela pode ser particularizada sob dois aspectos: por um lado, no sentido etnológico e quase religioso do termo, a escrita representa um rito de sepultamento; ela exorciza a morte introduzindo-a no discurso. Por outro lado, tem uma função simbolizadora; permite a uma sociedade situar-se, dando-lhe, na linguagem, um passado, e abrindo assim um espaço próprio para o presente: "marcar" um passado, é dar um lugar à morte, mas também redistribuir o espaço das possibilidades, determinar negativamente aquilo que está por fazer e, consequentemente, utilizar a narratividade, que enterra os mortos, como um meio de estabelecer um lugar para os vivos. A arrumação dos ausentes é o inverso de uma normatividade que visa o leitor vivo, e que instaura uma relação didática entre o remetente e o destinatário. (CERTEAU, 2008, p. 107)

Michel de Certeau está discutindo um interessante tópico chamado $O$ lugar do morto e o lugar do leitor, na constituição da escrita da História e da escrita literária em si. Sob este prisma, a rica simbologia de que se compõem os poemas de Inenigmática, assentada no labor artístico-literário, solicita de seu público leitor um refinamento, em termos de sensibilidade, atenção e percepção que vivificam a escrita e o leitor. Porém, não circunscreve a exigência elitista clássica de um leitor sublime; passa, aliás, a ultrapassar essa possibilidade, à medida que 
também pede desprendimento e voos imaginativos em zonas inalcançáveis pela razão - ao alcance, entretanto, de qualquer pessoa.

O texto poético, assim, não descura do fato de que seu horizonte de recepção irá fazê-lo se chocar com a sociedade massificada. Inevitável contato faz necessária redes de comunicação: o poema falará a todos e não desprezará as circunstâncias externas a si, pois que é preciso saber prever seu interlocutor. $\mathrm{O}$ que nos parece intrigante, porém, é a impressão de que, de alguma forma, a obra escolhe seu público.

\section{Referências}

CERTEAU, Michel de. A escrita da História. Tradução de Maria de Lourdes Menezes. Rio de Janeiro: Forense Universitária, 2ª edição, 2008.

FOUCAULT, Michel. A ordem do discurso. São Paulo: Edições Loyola, 2008.

ISER, Wolfgang. $O$ ato da leitura: uma teoria do efeito estético. Tradução de Johannes Kretschmer.

São Paulo: Editora 34, v. 1, 1996.

LIMA, Dilson Solidade. Inenigmática. São Paulo: Scortecci, 2014.

PAZ, Octavio. O arco e a lira. Tradução de Olga Savary. Rio de Janeiro: Nova Fronteira, 1982.

PIGLIA, Ricardo. O último leitor. Tradução de Heloísa Jahn. São Paulo: Companhia das Letras, 2006. RESENDE, Beatriz. A literatura brasileira na era da multiplicidade. IN: Contemporâneos: expressões da literatura brasileira no século XXI. Rio de Janeiro: Casa da Palavra/Biblioteca Nacional, 2008. SPROVIERO, Mario Bruno. Entropia: "Progresso" para a Destruição! Editora Mandruvá, julho de 2007. Disponível em: <http://www.hottopos.com/vdletras2/mario.htm>. Acesso em 5 abr.2016. 